\title{
Granulomatous rosacea: a case report
}

\author{
A. Kelati ${ }^{*}$ and F. Z. Mernissi
}

\begin{abstract}
Background: Granulomatous rosacea is a rare chronic inflammatory skin disease with an unknown origin. The role of Demodex follicularum in its pathogenesis is currently proved.

Case presentation: We report a case of a 54-year-old Moroccan man with a 3-month history of erythematous, nonpruritic papules on the lateral side around the eyes. Dermoscopy and histology confirmed the diagnosis of granulomatous rosacea.
\end{abstract}

Conclusions: We describe another clinical presentation of granulomatous rosacea with a clinical-dermoscopicpathological correlation.

Keywords: Granulomatous rosacea, Rare clinical form, Dermoscopy, Histology, Case report

\section{Background}

Granulomatous rosacea (GR) is a rare chronic inflammatory skin disease reported primarily in middle-aged women [1]. It is thought to be a particular form of rosacea on the basis of unique clinical and histological findings of granulomas; it is characterized by erythematous papules most commonly affecting the face; and it tends to have a chronic course [2]. We present the case of a 54year-old man with a 3-month history of GR associated with demodecidosis.

\section{Case presentation}

A 54-year-old Moroccan man with a history of psoriasis in remission presented with a 3-month history of erythematous nonpruritic lesions of the face with hypersensitivity to heat. A clinical examination revealed erythematous, telangiectatic, confluent papules of the lateral side around the eyes without any scales, crusts, or pustules. In the differential diagnosis, we included GR, sarcoidosis, lupus vulgaris, and lupus erythematosus tumidus. Dermoscopy revealed linear vessels characteristically arranged in a polygonal network, creamy and whitish linear areas, and white grayish plugs surrounded by an erythematous halo filling the follicular openings (Fig. 1).

* Correspondence: awatkelati@gmail.com

Department of Dermatology, University Hospital Hassan II, 202 Hay Mohamadi, Fez, Morocco
Histological examination of a punch biopsy specimen of the lesion showed granulomatous dermatitis with the presence of Demodex folliculorum on the biopsied tissue. These clinical, dermoscopic, and histological findings were consistent with the diagnosis of GR (Fig. 2), and the patient was treated with topical metronidazole for a total of 10 weeks, which led to a significant improvement.

\section{Discussion}

The role of Demodex in GR's pathogenesis was debated in the last decade, with recent data highlighting its significant role in triggering GR [3]. Our observation confirmed that this mite plays an important role in stimulation of the immune system and the formation of granulomas in GR in unusual sites. In our patient, the presence of Demodex in the follicular openings was confirmed by histology, and we noticed that a granulomatous infiltrate was agglomerated around the pilosebaceous follicles containing the mite. Dermoscopy confirms the presence of the characteristic vascular polygons, not only in conventional rosacea $[4,5]$ but also in GR. In our patient, we also noticed the most indicative dermoscopic whitish features of demodicidosis, called Demodex tails and Demodex follicular openings [6, 7].

\section{Conclusions}

We report an original observation of GR with a rare localization and an association with demodicidosis. 


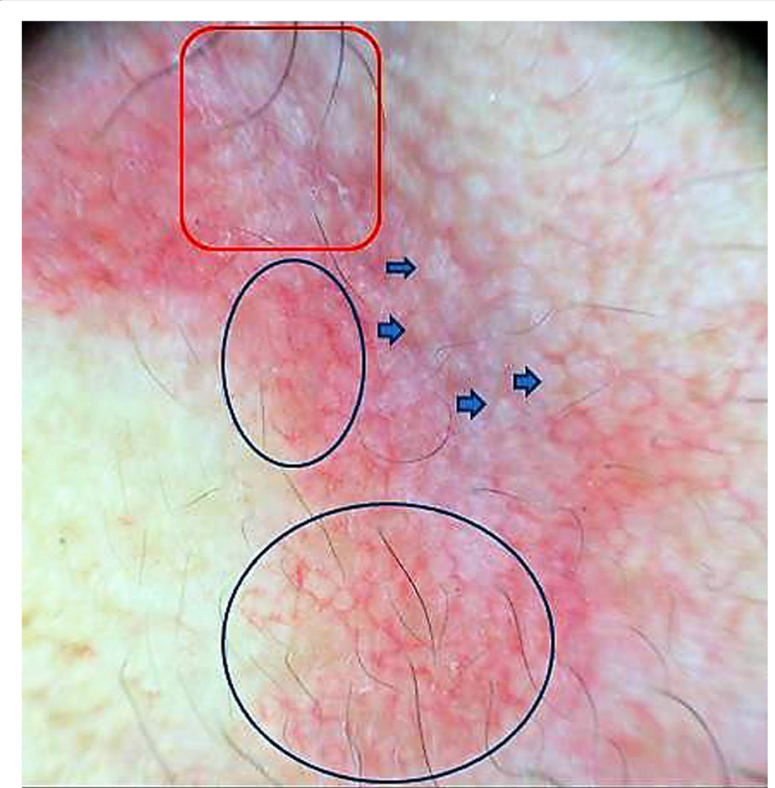

Fig. 1 Granulomatous rosacea. Dermoscopy reveals follicular openings containing white grayish plugs (Demodex follicular openings) (blue arrows), creamy whitish linear structures filling the follicular openings (Demodex tails) (red rectangle), and polygonal vessels (blue circles)

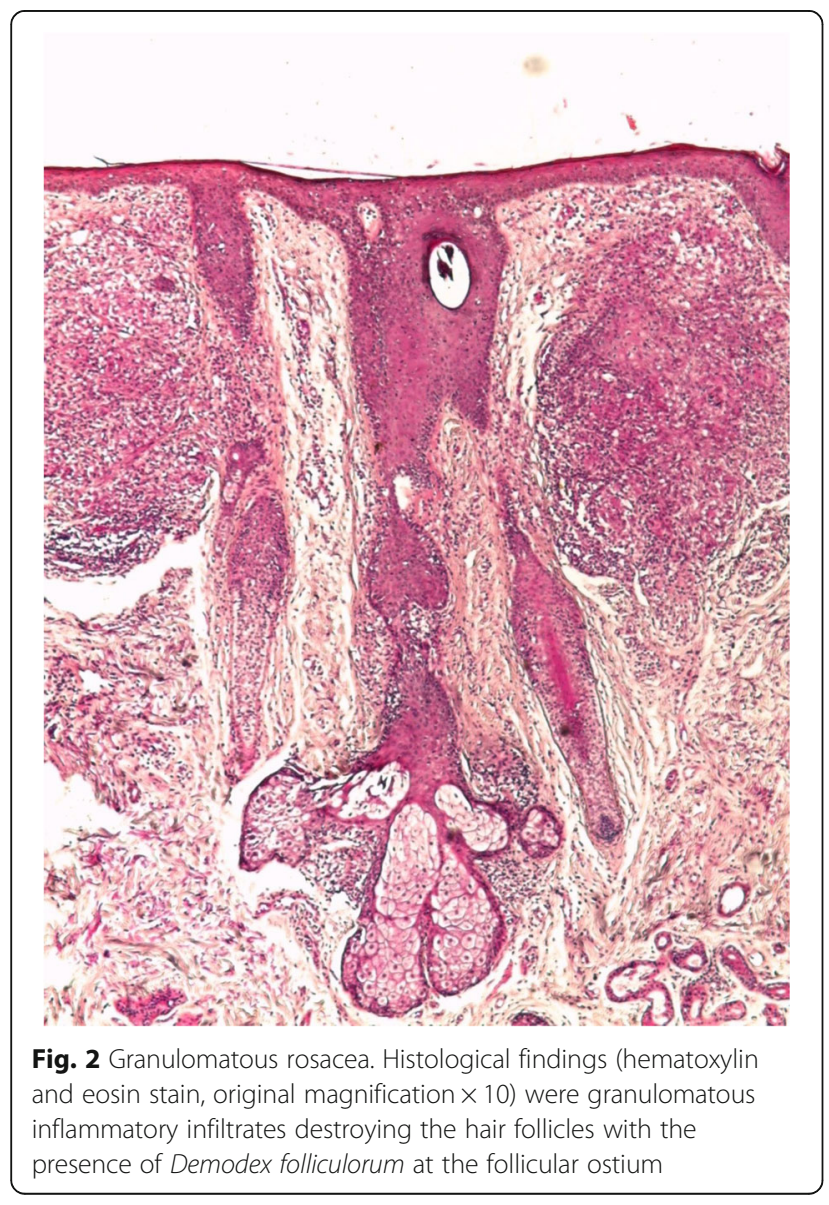

\section{Acknowledgements}

We are indebted to the patient, who gave us his consent for publication. We thank the medical staff of the department of anatomopathology for their enormous help.

\section{Availability of data and materials}

Please contact the authors for data requests.

\section{Authors' contributions}

AK drafted the manuscript. AK and FZM revised the manuscript critically for important intellectual content. Both authors read and approved the final manuscript.

\section{Ethics approval and consent to participate}

The patient was informed and gave his informed consent.

\section{Consent for publication}

Written informed consent was obtained from the patient for publication of this case report and any accompanying images. A copy of the written consent is available for review by the Editor-in-Chief of this journal.

\section{Competing interests}

The authors declare that they have no competing interests.

\section{Publisher's Note}

Springer Nature remains neutral with regard to jurisdictional claims in published maps and institutional affiliations.

Received: 13 December 2016 Accepted: 23 July 2017

Published online: 20 August 2017

\section{References}

1. Khokhar O, Khachemoune A. A case of granulomatous rosacea: sorting granulomatous rosacea from other granulomatous diseases that affect the face. Dermatol Online J. 2004;10(1):6.

2. Lee GL, Zirwas MJ. Granulomatous rosacea and periorificial dermatitis: controversies and review of management and treatment. Dermatol Clin. 2015;33(3):447-55.

3. Helm KF, Menz J, Gibson LE, Dicken CH. A clinical and histopathologic study of granulomatous rosacea. J Am Acad Dermatol. 1991;25(6):1038-43.

4. Lallas A, Argenziano G, Apalla Z, Gourhant JY, Zaballos P, Di Lernia V, et al. Dermoscopic patterns of common facial inflammatory skin diseases. J Eur Acad Dermatol Venereol. 2014;28(5):609-14.

5. Lallas A, Argenziano G, Longo C, Moscarella E, Apalla Z, Koteli C, et al. Polygonal vessels of rosacea are highlighted by dermoscopy. Int J Dermatol. 2014:53(5):e325-7.

6. Segal R, Mimouni D, Feuerman H, Pagovitz O, David M. Dermoscopy as a diagnostic tool in demodicidosis. Int J Dermatol. 2010;49(9):1018-23.

7. Errichetti E, Stinco G. Dermoscopy in general dermatology: a practical overview. Dermatol Ther (Heidelb). 2016;6(4):471-507.

Submit your next manuscript to BioMed Central and we will help you at every step:

- We accept pre-submission inquiries

- Our selector tool helps you to find the most relevant journal

- We provide round the clock customer support

- Convenient online submission

- Thorough peer review

- Inclusion in PubMed and all major indexing services

- Maximum visibility for your research

Submit your manuscript at www.biomedcentral.com/submit

O) BioMed Central 